\title{
Tiroid Hastalıkları ve Erektil Disfonksiyon
}

\author{
Thyroid Disease and Erectile Dysfunction
}

Ayten OĞUZ

KahramanmaraşS Sütçü İmam Üniversitesi Tipp Fakültesi, Endokrinoloji Bilim Dal, Kahramanmaraş

Geliş tarihi: 10.01.2020 Kabul tarihi: 03.02.2020 DOI: 10.17517/ksutfd.579134

Özet

Erektil disfonksiyon (ED) hasta ve partnerinin yaşam kalitesini önemli derecede etkileyen, seksüel ve üreme fonksiyonunu bozan çok yönlü bir hastalıktır. ED birçok hastalıkla ilişkilidir. ED ve tiroid hormonları arasındaki ilişki ile ilgili veriler sınırlı olmakla birlikte, ED tiroid disfonksiyonlu erkeklerde yaygın olarak görülür. Ötiroidizmin sağlanması ile düzelir. Bu nedenle ED’li erkeklerde tiroid fonksiyonları taranmalı ve ötiroidizm sağlanmadan spesifik tedavi yapılmamalıdır. Bu derlemede literatür ışı̆̆ında tiroid hastalıklarında ED yönetimi sunulmuştur.

Anahtar Kelimeler: Erektil disfonksiyon, üreme, tiroid hormonu

\begin{abstract}
Erectile dysfunction (ED) is a very common multifaceted disorder that significantly affects the patient's and partner's quality of life, with a detrimental effect on sexual and reproductive activity. ED is associated with many diseases. Although there is limited data about the relationship between ED and thyroid hormones, ED is commonly seen in men with thyroid dysfunction. ED is improved with the ensuring of euthyroidism. Therefore, thyroid function in men with ED should be screened and specific treatment should not be done without ensuring euthyroid state. In this review, the management of ED associated with thyroid disease is presented in the light of the literature.
\end{abstract}

Key word: Erectile dysfunction, reproduction, thyroid hormone

Yazışma Adresi: Ayten Oğuz Kahramanmaraş Sütçü İmam Üniversitesi Tip Fakültesi İç Hastalıkları AD, Endokrinoloji ve Metabolizma Hastalıkları Bilim Dalı, Kahramanmaraş Telefon: 05427863018 e-mail: aytenoguz@windowslive.com

ORCID No: 0000-0002-9518-8610 


\section{TİROİD ve SEKSÜEL FONKSIYYN}

Erektil disfonksiyon (ED), seksüel birleşme için yeterli penil ereksiyona ulaşma veya koruma kabiliyetinde devamlı veya tekrarlayıcı yetersizlik olarak tanımlanmaktadır (1). ED seksüel ve üreme fonksiyonunu bozan çok yönlü bir hastalıktır. Gonadal, hipofizer ve tiroid hormonları (TH) seksüel fonksiyonun kontrolünde önemli role sahiptirler. Tiroid hormonları neredeyse her biyolojik endokrin sistem ile bağlantılı olup cinsel farklılaşma ve gonadal gelişimde de önemli rol oynarlar. Kadın reprodüktif gelişimi üzerine TH’lerin etkileri iyi bilinirken (2,3), son zamanlarda androjen aksı ve TH'ler arasında da direkt etkileşim olduğu gösterilmiştir $(4,5)$. Bu bulgular TH'lerin erkeklerde hipotalamus-hipofiz-gonad aksı üzerinden gonadotropin üretimi düzenlenmesinde ve cinsiyet belirleyici genler ile doğrudan etkileşimle cinsel maturasyonda önemli bir etkiye sahip olduğunu göstermektedir. Ayrıca TH'ler steroidojenik enzim aktivitesini direkt ve indirekt olarak etkileyerek androjen biyosentezini düzenlerler (6-13). Tiroid hormonları biyolojik etkilerini TH reseptörlerine (TR) bağlanarak gösterirler. Hem rat hem de insan korpora kavernoza endotel ve düz kas hücrelerinde alfa ve beta nükleer TR gösterilmiştir (14). Ayrıca hipertiroidili hayvan modellerinde korpora kavernosanın nitrik oksit bağıml relaksasyonunda bozulma olduğu bildirilmiştir (15). Bu veriler TH'lerin penil nitrik oksit formasyonunu etkilediğini de desteklemektedir.
Tiroid hormonlarının üreme sistemi üzerine etkileri ile ilgili birçok hayvan ve insan çalışması yapılmıştır ve genellikle tiroid fonksiyonlarındaki değişikliklerin fertilite ve cinsel aktivitede azalma ile sonuçlandığı gösterilmiştir $(6,17)$. Ancak, altta yatan mekanizmalar bütün türlerde sabit değildir ve çalışmalarda farklı sonuçlar elde edilmiştir (6-13)

\section{Tiroid Hormonlarının Testiküler Etkileri}

Sertoli hücreleri gelişmekte olan germ hücrelerinin desteklenmesi ve beslenmesini sağlar. Her bir sertoli hücresi sınırlı sayıda germ hücresine destek sağlar. Sertoli hücre sayısı testisteki günlük sperm üretiminin bir göstergesidir. Sertoli hücrelerinden eksprese edilen belli genler ve proteinler bu hücrelerin maturasyonu ile ilişkilidir ve TH'lerin bu proteinleri etkileyebileceği gösterilmiştir (18). Ayrıca birçok hayvan çalışmalarında TH’lerin leydig hücre gelişimini ve steroidogenezi düzenlediği de gösterilmiştir (19,20). Leydig hücreleri kolesterolden steroid hormonlarını sentezler (6). Triiyodotironinin doz bağımlı olarak leydig hücrelerinde testosteron üretimini uyardığı gösterilmiştir (20-22). Tiroksin (T4) verilerek tirotoksikoz oluşturulmasının da testosteron miktarını arttırdığı, gonadotropin seviyelerini ise azalttığ gösterilmiştir (23). Ancak yüksek T4 dozlarında testis ve seminal vezikül ağırlığında azalma olduğu da bildirilmektedir (16).

\section{Tablo 1. Hipertiroid ve hipotiroid erkeklerdeki homonal değişiklikler}

\begin{tabular}{|l|c|c|} 
& Hipertiroidi & Hipotiroidi \\
\hline SHBG & $\uparrow$ & $\downarrow / \mathrm{N}$ \\
\hline Estradiol & $\mathrm{N} / \uparrow$ & $\mathrm{N}$ \\
\hline Androjenlerinmetabolikklirens oranı & $\downarrow$ & - \\
\hline Serbest estradiol & $\uparrow$ & $\downarrow$ \\
\hline Testosteron & $\uparrow$ & $\downarrow$ \\
\hline Androstenedion & - & $\downarrow$ \\
\hline DHEA & $\uparrow$ & $\downarrow$ \\
\hline Serbest Testosteron & $\uparrow$ & - \\
\hline Bioavailable Testosteron & $\uparrow$ & $\downarrow$ \\
\hline Testoseron-Androstenedion dönüşümü & $\uparrow$ & - \\
\hline Androjen-estron dönüşümü & $\uparrow$ & - \\
\hline Progesteron & $\uparrow / \rightarrow$ & $\mathrm{N}$ \\
\hline LH & $\uparrow /$ & $\mathrm{N}$ \\
\hline FSH & $\uparrow$ & $\downarrow$ \\
\hline GnRH sonrası & $\uparrow$ & $\downarrow$ \\
\hline LH & $\uparrow$ & $\downarrow$ \\
\hline FSH & $\uparrow$ & $\downarrow$ \\
\hline
\end{tabular}




\section{Tiroid Disfonksiyonu ve Erektil Disfonksiyon}

Tiroid hormonlarının ED’deki rolü ile ilgili sınırlı veri bulunmaktadır. Hipertiroidizm ve hipotiroidizmin kadın gonadal fonksiyonlara etkileri açıkça bilinmesine rağmen bu hastalıkların erkek üreme fonksiyonlarına etkisi tartışmalıdır $(24,25)$.

\section{HIPPETIROIDİ}

\section{Hormonal değişiklikler}

Hipertiroidi ile ilişkili olarak seks hormon bağlayıcı globulin (SHBG)'de artı̣s dolaşımdaki total testosteron seviyelerinde artışa ve testosteron metabolik klirensinde azalmaya yol açar (26). Ancak hipertiroid erkeklerde serbest testosteron konsantrasyonları genellikle normaldir. Total ve serbest estradiol (E2) konsantrasyonları ise sıklıkla yüksek ve sonuç olarak serbest testosteron/serbest E2 oranı normal bireylerle karşılaştırıldığında hipertiroid erkeklerde daha düşüktür $(27,28)$. Ayrıca hipertiroid erkeklerde testosteron cevabını değerlendirmek için verilen insan koryonik gonadotropine (HCG) leydig hücrelerinin körleşmiş yanıtına karşın, gonadotropin salgılatıcı hormon $(\mathrm{GnRH})$ verilmesine abartılı luteinize edici hormon ve follikül uyarıcı hormon yanıtı görülür (Tablo 1). Hipotalamo-hipofizer-gonadal akstaki bu değişiklikler artmış T4 seviyesi ile ilişkilidir ve ötiroidizmin sağlanması ile düzelirler. Bu yüzden spesifik tedavi gerekli değildir (28).

SHBG, seks hormon bağlayıc globulin; DHEA, dehidroepiandrosteron; LH, luteinize edici hormon; FSH, follikülstimüle edici hormon; GnRH, gonadotropin salgılatıcı hormon; $\mathrm{N}$, normal

\section{Spermatogenez ve fertilite}

Hipertiroidinin semen kalitesine etkisi birkaç çalı̧̧mada gösterilmiștir. Bu çalışmalarda hipertiroid erkeklerde sperm motilitesinde azalma ve oligospermi bildirilmiştir. Ayrıca tirotoksikozun tedavisi sonrasında hem sperm motilitesi hem de sperm dansitesinin düzeldiği görülmüştür (29-33).

Hipertiroidizm ile ilgili bir diğer endişe seksüel davranışlara olan etkisidir. Hipertiroid erkeklerde, normal bazal testosteron konsantrasyonlarına rağmen \%70'e varan oranlarda ED gözlemlenmiştir (34). Ayrıca, küçük bir vaka serisinde hipertiroidili birçok erkekte seksüel disfonsiyonun bazı formları (cinsel isteksizlik, prematür veya gecikmiş ejekülasyon veya $\mathrm{ED}$ ) görülebileceği ileri sürülmüştür (35). Tersine ED’li erkeklerin, küçük bir kısmında hipertiroidi bildirilmiştir (36). Yüksek T4 seviyelerinin ED’ye nasıl neden olduğu tam olarak bilinmemektedir. Hipertiroidili erkeklerde SHBG ve total testosteron seviyeleri daha yüksek saptanmakla birlikte serbest testosteron seviyeleri normaldir (37). Hipertiroidizm ile ilişkili yorgunluk, myalji ve sinirlilik ve depresyon gibi ruhsal değişiklikler de seksüel disfonksiyona katkıda bulunabilir. Hipertirodinin tedavisi sonrasında ED, cinsel isteksizlik ve gecikmiş veya prematür ejakülasyonun düzeldiği bildirilmiştir (35). Ayrıca sex steroidlerinin ölçümü ve semen analizlerinin de ötiroidizm sağlandığında normale döndüğü görülmüştür (38).

Sonuç olarak, ED hipertiroid erkeklerde oldukça yaygın görülmekte olup tedavi ile düzelmektedir. Bu nedenle ED'li tüm erkeklerde tiroid fonksiyonlarının taranması gerektiği ve ED spesifik tedavisinin ötiroidizm sağlandıktan 6 ay sonrasına kadar ertelenmesi önerilmektedir.

\section{Radyoaktif İyot Tedavisi ve Üreme}

Radyoaktif iyot-131 (RAI-131) tedavisi hipertiroidi tedavisinde yaygın kullanılır. Radyasyonun gonadlar üzerinde potansiyel mutajenik etkilerinden dolayı genç hastalarda üreme fonksiyonlarını etkileme ile ilgili muhtemel endişeler vardır. Çeşitli çalışmalarda RAI-131 tedavisi sonrası hipertiroidili erkeklerde, normal üreme performansı bildirilmiştir. $\mathrm{Bu}$ nedenle RAI tedavisi klinisyenler tarafindan hipertiroidi tedavisinde ilk seçenek tedavide kullanılmaktadır (39). Tiroid kanseri tedavisi ile ilgili olarak ise, multipl ve yüksek dozda RAI tedavisinin gonadal fonksiyonları olumsuz etkileyebileceği gösterilmiştir (40). Birkaç çalışmada differansiye tiroid kanserinde kullanılan özellikle yüksek doz RAI tedavisinin testiküler fonksiyonlarda geçici bozulmaya neden olabileceği bildirilmiştir (41).

\section{HIPOTIROIDİ}

\section{Hormonal değișiklikler}

Hipotiroidizm erkeklerde kadınlardan daha az görülür ve üreme fonksiyonları üzerine etkisi hakkında daha az kesinleşmiş bilgiler vardır. Primer hipotiroidi, SHBG ve total testosteronda azalmaya yol açar ve yaklaşık \%60 oranında serbest testosteron konsantrasyonunu da azaltır (42). Birçok çalışmada hipogonadizmli hipotiroid erkeklerin normal LH ve FSH düzeylerine sahip olduğu görülmüştür (28) (Tablo 1). Ancak primer defektin Leydig hücrelerinde olmadığı ve muhtemelen hipotalamus ve/veya hipofizer seviyelerdeki defektin sonucu olduğu gösterilmiştir. Primer hipotiroidi de hipofiz bezinin GnRH'ya körelmiş yanıtı ve HCG’ye abartılı testosteron yanıtı bu düşünceyi desteklemektedir (43). Bunun dişında primer hipotiroidide hipotalomo-hipofizer-gonadal akstaki bozulma sonucunda serbest testosteron subnormal seviyelerdedir (44). Ayrıca hipotiroidili erkeklerde dehidroepiandrosteron (DHEA), DHEA sülfat, androstenedion ve pregnenolone sülfat seviyeleri normal bireylere göre daha düşük saptanmıştır $(28,45)$ (Tablo 1$)$.

\section{Spermatogenez ve fertilite}

Hipotiroidinin spermatogenez üzerine olumsuz etkisi ile ilgili literatürde sınırlı veri mevcuttur. Krassas ve ark.'nın çalışmasında, hipotiroid erkekler kontrol grubu ile semen parametreleri açısından karşılaştırılmış ve sadece sperm morfolojisi açısından anlamlı fark saptanmıştır. Ayrıca ötirodizm sağlandıktan sonra sperm morfolojisinin düzeldiği de gösterilmiştir (46). Nikoobakht ve ark.'nın çalışmasında da, aşikar 
hipotiroidinin semen parametreleri üzerine olumsuz etkisi olduğu bildirilmiştir (47).

Hipotiroid erkeklerde seksüel disfonkiyon sıklığı da tam olarak bilinmemektedir. Ancak erkek hipotiroidi hastalarında cinsel işlev bozukluğu ve özellikle ED arasında ilişki olduğunu gösteren çok sayıda rapor vardır (42). Altıyüz ED’li erkeğin alındığı bir çalışmada hipotiroidi prevalansı \%6 olarak bildirilmiştir (46). Krassas ve ark.'nın bir başka çalışmasinda, hipotiroid erkeklerde ED oranı kontrol grubuna göre daha yüksek saptanmıştır (sırasıyla, \%63, \%34) (48). Corona ve ark. çalışmasında da, TSH ve ED arasında anlamlı zıt ilişki gösterilmiştir (49). Hipotiroidi ile ilişkili yorgunluk, depresyon ve mood değişiklikleri de, her iki cinste seksüel disfonksiyona katkıda bulunabilir (35). Aynı zamanda hipotiroid erkeklerde görülen düşük SHBG ve serbest testosteron konsantrasyonları seksüel disfonksiyona katkıda bulunabilir (36). Küçük bir gözlemsel çalışmada, cinsel isteksizlik ve ED’nin hipotiroidi tedavisi ile düzeldiği bildirilmiştir (35). Tiroksin replasmanı sonrası SHBG ve serbest testosteron seviyelerinin de normalize olduğu gösterilmiştir $(36,47)$.

Ancak Poppe ve ark. çalışmasında, infertil erkeklerde hipotiroidi prevalansı yüksek saptanmamış ve bu hastalarda tiroid disfonksiyonu açısından rutin tarama önerilmemiştir (50). Corona ve ark.'nın çalışmasında da, hipertiroidi ve ED arasında ilişki varken primer hipotiroidi ile ED arasında ilişki saptanmamıştır. Bu nedenle bu çalışmada ED’li hastalarda rutin tiroid fonksiyon taraması önerilmemiştir (49).

Sonuç olarak, hipertiroidi ve hipotiroidi erkek üreme fonksiyonunda olumsuz etkilere yol açar. Literatürde farklı veriler olmakla birlikte ED’li birçok hastada tiroid disfonksiyonu rol oynar ve tedaviyle tiroid disfonksiyonunun normalizasyonu ED’yi düzeltir. Bu nedenle de tüm ED’li hastalarda rutin tiroid fonksiyon değerlendirilmesi yapılmalıdır.

\section{KAYNAKLAR}

1. Lizza EF, Rosen RC. Definition and classification of erectile dysfunction:report of the Nomenclature Committee of the International Society of Impotence Research. Int J Impot Res 1999;11:141

2. Habibi HR, Nelson ER, Allan ER. New insights into thyroid hormone function and modulation of reproduction in goldfish. Gen Comp Endocrinol. 2012;175(1):19-26

3. Doufas AG, Mastorakos G. The hypothalamic-pituitary-thyroid axis and the female reproductive system. Ann N Y Acad Sci. 2000;900:65-7

4. Wagner MS, Wajner SM, Maia AL. The role of thyroid hormone in testicular development and function. J Endocrinol. 2008;199(3):351-65

5. Wagner MS, Wajner SM, Maia AL. Is there a role for thyroid hormone on spermatogenesis? Microsc Res Tech. 2009;72(11):796808

6. Flood DE, Fernandino JI, Langlois VS. Thyroid hormones in male reproductive development: evidence for direct crosstalk between the androgen and thyroid hormone axes. Gen Comp Endocrinol. 2013;192:2-14

7. Manna PR, Kero J, Tena-Sempere M, Pakarinen P, Stocco DM, Huhtaniemi IT. Assessment of mechanisms of thyroid hormo- ne action in mouse Leydig cells: regulation of the steroidogenic acute regulatory protein, steroidogenesis, and luteinizing hormone receptor function. Endocrinology 2001;142:319-31.

8. Manna PR, Roy P, Clark BJ, Stocco DM, Huhtaniemi IT. Interaction of thyroid hormone and steroidogenic acute regulatory (StAR) protein in the regulation of murine Leydig cell steroidogenesis. J. Steroid Biochem. Mol. Biol. 2001;76:167-77

9. Antony FF, Aruldhas MM, Udhayakumar RCR, Maran RRM, Govindarajulu P. Inhibition of Leydig-cell activity in-vivo and in-vitro in hypothyroid rats. J. Endocrinol. 1995;144:293-300

10. Nagendra Prasad RJ, Datta M, Bhattacharya S. Differential regulation of Leydig cell 3beta-hydroxysteroid dehydrogenase/ delta5-delta4-isomerase activity by gonadotropin and thyroid hormone in a freshwater perch,Anabas testudineus. Comp. Biochem. Physiology. 1999; Part C 124:165-73

11. Biswas NM, Ghosh PK, Biswas R, Ghosh D. Effect of thyroidectomy, and thyroxine and alpha( $2 \mathrm{u})$-globulin replacement therapy on testicular steroidogenic and gametogenic activities in rats. J. Endocrinol. 1994;140:343-7

12. Ram PA, Waxman DJ. Pretranslational control by thyroid hormone of rat liver steroid 5 alpha-reductase and comparison to the thyroid dependence of two growth hormone-regulated CYP2C mRNAs. J. Biol. Chem. 1990;265:19223-9

13. Kala N, Ravisankar B, Govindarajulu P, Aruldhas MM. Impact of foetal onset hypothyroidism on the epididymis of mature rats. Int. J. Androl. 2002;25:139-48

14. Carosa E, Di Sante S, Rossi S, Castri A, D’Adamo F, Gravina GL, et al. Ontogenetic profile of the expression of thyroid hormone receptors in rat and human corpora cavernosa of the penis. J Sex Med. 2010;7(4 Pt 1):1381-90

15. Ozdemirci S, Yildiz F, Utkan T, Ulak G, Cetinaslan B, Erden F et al. Impaired neurogenic and endothelium-dependent relaxant responses of corpus cavernosum smooth muscle from hyperthyroid rabbits. Eur J Pharmacol. 2001;428(1):105-11

16. Krassas GE. The male and female reproductive system in thyrotoxicosis. In: Braverman LE, Utiger RD, eds. Werner and Ingbar's the thyroid-a fundamental and clinical text. 9th ed. Philadelphia: Lippincott Williams \&Wilkins;2005:621-8

17. Johnson CA. Thyroid issues in reproduction. Clin Tech Small Anim Pract 2002;17:129-32

18. Sharpe RM, McKinnell C, Kivlin C, Fisher JS. Proliferation and functional maturation of Sertoli cells, and their relevance to disorders of testis function in childhood. Reproduction 2003; 125:769-84

19. Buzzard JJ, Wreford NG, Morrison JR. Thyroid hormone, retinoic acid, and testosterone suppress proliferation and induce markers of differentiation in cultured rat Sertoli cells. Endocrinology 2003;144:3722-31

20. Jana NR, Bhattacharya S. Binding of thyroid hormone to goat testicular cell induces generation of a proteinaceous factor which stimulates androgen release. J Endocrinol 1994;143:549-56

21. Hardy MP, Kirby JD, Hess RA, Cooke PS. Leydig cell increase their numbers but decline in steroidogenic function in the adult after neonatal hypothyroidism. Endocrinology 1993;132:241720

22. Maran RR, Arunakaran J, Aruldhas MM. T3 Directly stimulates basal and modulates LH induced testosterone and estradiol production by rat Leydig cells in vitro. Endocrine J 2000;47:417-28

23. Manna PR, Tena-Sempere M, Huhtaniemi IT. Molecular mechanisms of thyroid hormone-stimulated steroidogenesis in mouse leydig tumor cells. J Biol Chem 1999;274:5909-18

24. Chandrasekhar Y, Holland MK, D’Occhio MJ, Setchell BP. Spermatogenesis, seminal characteristics and reproductive hormone 
levels in mature rams with induced hypothyroidism and hyperthyroidism. J Endocrinol 1985;105:39-46

25. Krassas GE. Thyroid disease and female reproduction (modern trends). Fertil Steril 2000;74:1063-70

26. McDermott MT. Thyroid disease and reproductive health. Thyroid 2004;14(Suppl 1):1-3

27. Ruder H, Corvol P, Mahoudeau JA, Ross GT, Lipsett MB. Effects of induced hyperthyroidism on steroid metabolism in man. J Clin Endocrinol Metab 1971;33:382-7

28. Krassas GE, Poppe K, Glinoer D. Thyroid function and human reproductive health. Endocr Rev. 2010;31(5):702-55

29. Abalovich M, Levalle O, Hermes R, Scaglia H, Aranda C, Zylbersztein $\mathrm{C}$, et al. Hypothalamic-pituitary-testicular axis and seminal parameters in hyperthyroid males. Thyroid 1999;9:85763

30. Krassas GE, Pontikides N. Male reproductive function in thyroid alterations. Best Pract Res Clin Endocrinol Metab 2004;18:183-95

31. Clyde HR, Walsh PC, English RW. Elevated plasma testosterone and gonadotropin levels in infertile males with hyperthyroidism. Fertil Steril 1976;27:662-6

32. Kidd GS, Glass AR, Vigersky RA. The hypothalamicpituitary-testicular axis in thyrotoxicosis. J Clin Endocrinol Metab 1979;48:798-802

33. Hudson RW, Edwards AL. Testicular function in hyperthyroidism. J Androl 1992;13:117-24

34. Meikle AW. The interrelationships between thyroid dysfunction and hypogonadism in men and boys. Thyroid 2004;14 (Suppl 1):17-25

35. Carani C, Isidori AM, Granata A, Carosa E, Maggi M, Lenzi A, et al. Multicenter Study on the Prevalence of Sexual Symptoms in Male Hypo- and Hyperthyroid Patients. J Clin Endocrinol Metab 2005;90:6472-9

36. Veronelli A, Masu A, Ranieri R, Rognoni C, Laneri M, Pontiroli AE. Prevalence of erectile dysfunction in thyroid disorders: comparison with control subjects and with obese and diabetic patients. Int J Impot Res 2006;18:111-4

37. Chopra IJ, Tulchinsky D. Status of estrogen-androgen balance in hyperthyroid men with Graves' Disease. J Clin Endocrinol Metab 1974;38:269-77

38. Corona G, Petrone L, Mannucci E, Jannini EA, Mansani R, Magini A, et al. Psycho-biological correlates of rapid ejaculation in patients attending an andrologic unit for sexual dysfunctions. Eur Urol 2004;46:615-22

39. Hayek A, Chapman EM, Crawford JD. Long-term results of treatment of thyrotoxicosis in children and adolescents with radioactive iodine. N Engl J Med 1970;283:949-53

40. Mazzaferri EL, Jhiang SM. Long-term impact of initial surgical and medical therapy on papillary and follicular thyroid cancer. Am J Med 1994;97:418-28

41. Krassas GE, Pontikides N. Gonadal effect of radiation from 131I in male patients with thyroid carcinoma. Arch Androl 2005;51:171-5

42. Gabrielson AT, Sartor RA, Hellstrom WJG. The Impact of Thyroid Disease on Sexual Dysfunction in Men and Women. Sex Med Rev. 2019;7(1):57-70

43. Vela'zquez EM, Bellabarba Arata G. Effects of thyroid status on pituitary gonadotropin and testicular reserve in men. Arch Androl 1997;38:85-92

44. Gordon GG, Southren AL, Tochimoto S, Rand JJ, Olivo J. Effect of hyperthyroidism and hypothyroidism on the metabolism of testosterone and androstenedione in man. J Clin Endocrinol Metab 1969;29:164-70
45. Tagawa N, Takano T, Fukata S, Kuma K, Tada H, Izumi Y, et al. Serum concentration of androstenediol and androstenediol sulfate in patients with hyperthyroidism and hypothyroidism. Endocr J 2001;48:345-54

46. Krassas GE, Papadopoulou F, Tziomalos K, Zeginiadou T, Pontikides N. Hypothyroidism has an adverse effect on human spermatogenesis: a prospective, controlled study. Thyroid 2008; 18:1255-9

47. Nikoobakht MR, Aloosh M, Nikoobakht N, Mehrsay AR, Biniaz F, Karjalian MA. The role of hypothyroidism in male infertility and erectile dysfunction. Urol J 2012;9(1):405-9

48. Krassas GE, Tziomalos K, Papadopoulou F, Pontikides N, Perros P. Erectile dysfunction in patients with hyper- and hypothyroidism: how common and should we treat? J Clin Endocrinol Metab 2008;93:1815-9

49. Corona G, Wu FC, Forti G, Lee DM, O'Connor DB, O'Neill TW, et al; EMAS Study Group. Thyroid hormones and male sexual function. Int J Androl. 2012;35(5):668-79

50. Poppe K, Glinoer D, Tournaye H, Maniewski U, Haentjens P, Velkeniers B. Is systematic screening for thyroid disorders indicated in subfertile men? Eur J Endocrinol 2006;154(3):363-6 